\title{
Subjective burdens among informal caregivers of critically ill patients: a cross- sectional study in rural Shandong, China
}

Wenhao Fu ${ }^{1,2}$, Jiajia $\mathrm{Li}^{1,2^{*}}$, Feng Fang ${ }^{1,2}$, Dan Zhao ${ }^{1,2}$, Wenting Hao ${ }^{1,2}$ and Shixue $\mathrm{Li}^{1,2^{*}}$

\begin{abstract}
Background: Informal caregivers are the main source of care for the critically ill, especially after discharge or during the terminal stages at home. However, the concern for informal caregivers is often overshadowed by critically ill patients. The purpose of this study is to determine the influencing factors of the subjective burden of informal caregivers and to seek solutions accordingly.
\end{abstract}

Methods: Between July and August 2019, a cross-sectional study was conducted in Shandong, China, focusing on family caregivers and critically ill patients. Subjective caregiver burden was measured by the Chinese version of Zarit Burden Interview (ZBI). The stress process model was used to identify conditions relevant to the caregiving burden and to assess their impact on family caregivers.

Results: 554 samples were selected for analysis. The average scores of Zarit Caregiver Burden Interview (ZBI) scores in this study was $30.37 \pm 19.04(n=554)$. ZBI scores of older, less educated, and spouse caregivers were significantly lower $(4.12 ; 95 \% \mathrm{Cl}, 0.42$ to $7.81 ; \mathrm{P}=0.029)$. Objective and subjective burdens increased proportionally. Secondary role stress factors included the higher out-of-pocket (OOP) costs of critical diseases and lower household income, both of which increased caregivers' subjective burdens $(1.28 ; 95 \% \mathrm{Cl},-0.06$ to $2.63 ; \mathrm{p}=0.062)$. Formal medical aid systems played a positive role in reducing subjective caregiving burdens $(-7.31 ; 95 \% \mathrm{Cl},-13.23$ to $-1.40 ; \mathrm{p}=0.016)$.

Conclusions: Health policies should address both the direct medical burdens and the intangible psychological burdens of critical diseases.

Keywords: Informal caregiver, Subjective burden, Patients with critical illness, China

\section{Background}

As patient loads grow, informal care is an increasingly important part of health care systems. An informal caregiver provides unpaid support to a family member or friend [1,2]. Informal caregivers provide approximately $90 \%$ of long-term care for adults living at home in the United States [3], and an estimated $80 \%$ of care for

\footnotetext{
*Correspondence: lijiajia@sdu.edu.cn; shixueli@sdu.edu.cn

${ }^{1}$ Centre for Health Management and Policy Research, School of Public Health, Cheeloo College of Medicine, Shandong University, Jinan 250012, China

Full list of author information is available at the end of the article
}

non-self-sufficient patients in Europe [4]. Informal caregivers generally shoulder a heavier stress burden than formal nurses, due to longer hours, emotional exhaustion, and personal financial burden shared with their patients [5-8]. Such stress is known as "secondary role strains" in Pearlin's stress process model [9]. Informal caregivers suffer more health problems and depressive symptoms, as well lower self-reported family health than formal nurses [10-14]. This suffering is particularly acute among caregivers for patients suffering from critical illnesses, which has been described as 'we-disease' [13]. 
Critical illnesses are long-lasting, difficult-to-cure diseases with high financial costs that alter the lives of patients and their families over a long period of time [15-17]. In addition to causing physical injury and psychological stress to patients themselves, critical illnesses are also one of the main causes of patients' families falling into poverty $[14,18]$.

Family caregivers are the main source of care for the critically ill, especially after discharge from a hospital or during terminal stages at home. Caregivers of critically ill patients shoulder multidimensional challenges, including monitoring diseases, providing emotional support, and sharing financial burdens [19]. Such prolonged challenges may result in depression, stress, diminished physical health, and even an increased risk of heart disease [20-22]. The caregiving capacity and efficiency of informal caregivers may thus be impaired, interfering with the recovery of critically ill patients and creating a vicious cycle.

Caregiver burden is defined as a negative reaction to the impact of providing care on the caregiver's social, occupational, and personal roles [23]. In 1966, Hoenig and Hamilton extended this concept into subjective burden and objective burden [24]. The objective burden refers to the observable, tangible cost caused by the care- recipients' illness to the caregiver [25], while the subjective burden refers to the personal perception and personal evaluation of the extent of caregiving burden $[24,25]$. The subjective burden arising from caring for a frail or disabled relative can lead to emotional, mental, and physical health problems for caregivers [26, 27], however, may be overlooked by researchers because they are not directly visible [24]. Therefore, we need to pay more attention to the subjective burden.

Unfortunately, the subjective burden of caregivers can be unappreciated [28]. Even in countries like the United States, caregivers often lack direct support either as caregivers or as individuals [29]. Caregiver burden has been an issue of concern, with female gender, lower educational attainment, depression symptoms, social isolation, financial stress, and poor health status being risk factors for caregiver burden [30]. Among informal caregivers, Sspousal caregivers may shoulder morewere more likely to experience caregiver burden than other family members [31]. For caregivers of cancer patients, caregiver burden was heavier for those who were younger, male, single, and with primary school education or below [32]. However, Intas et. al., found that caregiving burden was not associated with caregiver's age or years of care for family caregivers of hemodialysis patients with chronic kidney disease-end stage. Han et al. 's study on the care burden of family caregivers of stroke survivors found that caregiver age and depressed mood, as well as care duration, were determinants of caregiver burden [33]. From the perspective of patient characteristics, existing studies found that their education level, functional status were not significantly associated with caregiver burden [12, 34, 35]. However, studies linking caregiver factors to patient factors that directly affect the intensity of care were fall from enough.

Moreover, although the government has carried out the Critical Illness Insurance to relieve the economic burden of the families with critically ill patients, their caregiving burden has not been paid enough attention by policy and research. We have limited knowledge of how to reduce the burden of the family caregivers for patients suffering from critical illness, particularly in the context of rural China. Professional nursing institutions and nursing staff are in short supply in China, especially in rural areas. Data from China Health Statistics Yearbook showed that there were only 2 nurses per 1000 in rural areas in 2019 [36]. Therefore, it is necessary to conduct a study in China that incorporates both information on patients with critical illness and their informal caregivers, as well as their family information, to comprehensively explore the factors associated with informal caregiver burden in rural patients with critical illness.

The purpose of this study was to answer what factors might be associated with caregiving burdens of the critically ill patients and to seek solutions accordingly. The underlying study applies and interrogates the stress process model, care need factors, objective burdens, secondary role strain factors, and caregiver backgrounds. Understanding the potential effects of protective and risk factors will help formulate targeted interventions to improve outcomes for family caregivers of critically ill patients.

\section{Methods}

\section{Study design and setting}

Between July and August 2019, a cross-sectional study was conducted in Shandong, China, a central province with a population of more than 100 million. Yantai, Weifang, and Heze were selected as representative regions from the eastern, central, and western parts of Shandong province, based on their socio-economic development, health resource distribution, population structures, and geography.

\section{Study population}

Informal caregivers were defined as those who (i) look after and assume primary responsibility for the care of patients; (ii) aged 18 years and above; (iii) not be paid ; (iiii)care critically ill patients and (iiiii) able to understand the contents of the interview and can communicate normally with the interviewer during the interview. Critically 
ill patients were defined as meeting at least one of the following criteria: 1) families with patients whose OOP (out-of-pocket) expenses exceed the local Critical Illness Insurance (CII) threshold; 2) Even if the single-phase OOP did not exceed the threshold, families with patients who suffered from diseases that are long-lasting and seriously impacts the patient's ability to obtain income or engage in daily living, such as hematopoietic stem cell transplantation and end-stage renal disease, sequelae of stroke and severe mental illness.

\section{Sampling method}

Patients with critical illness were selected in Shandong Province by stratified cluster sampling. Using the family as the unit, researchers approached informal caregivers who met the criteria and the corresponding patients with critical illness, respectively. The researchers provided them with an explanation about the study. Those willing to participate in the interview were asked to sign an informed consent form.

\section{Study procedure and process}

Caregivers answered questionnaires separately from corresponding patients with critical illness. Considering the generally low educational attainment of the rural residents, we took a face-to-face survey and interviewed, explained, and filled out questionnaires by the investigators. The investigators were divided into four groups, each of which checked the others for logical contradictions, missing data, and other problems at the end of each day. Questionnaire information was taken in the form of an interview filled out by a trained interviewer, avoiding illiteration of the respondent, and the occurrence of other errors in filling out the questionnaire. The interview took approximately 35-40 minutes to complete the questionnaire. Fig. 1 illustrates the conduct of the study. EpiData 3.1 was used for double data entry to ensure data accuracy. Stata 14.0 was used to clean the database.

\section{Study tools}

The caregiver stress process model proposed by Pearlin et al., which identifies perceived caregiver stress

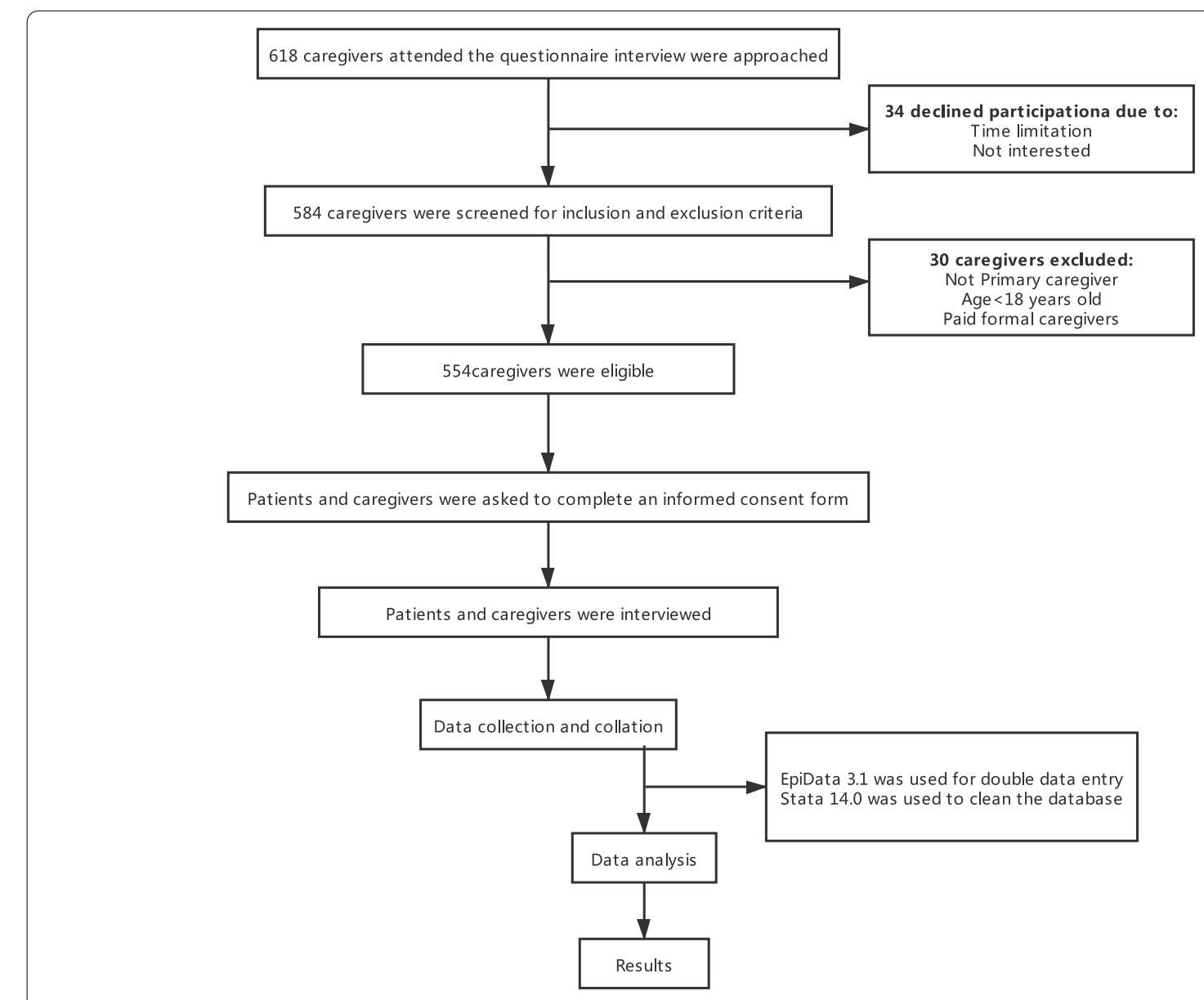

Fig. 1 Flow chart of the conduct of the study 
associated with caring for older adults, were served as a precise theoretical framework for understanding caregiver burden $[9,37,38]$. . Combined Tough's dyadic perspective with Pearlin's stress process model, five aspects were included in our study, including caregivers' background, care need, primary stressors, secondary strains, outcome [26]. According to Pearlin's and Judge's study family caregiver burdens derive from the primary stressor of providing sustainable care for patients, often involving patients' socioeconomic characteristics, resources, and self-rated health [26]. We use the subjective burden of caregiving as our dependent variable to represent the outcome. With reference to the study by Souza [20], Groenou [39] and Chou [40], Caregiving hours (objective burden) and patient care need (patient gender, patient age, patient education, patient self-related health, patient suffered from chronic diseases) were used as metrics for the primary stressor. The secondary role strain was assessed through a comprehensive set of indicators, including relationship with the care recipient, caregiving time, geographical location, savings, debt, total annual per capita income, OOP expenses, and medical system coverage (Fig. 2) [41]. Additionally, the caregivers' demographics (such as age, gender, and education) and their self-assessed health and employment statuses were incorporated into the model according to Tough's [26], Zarit [42], Oldenkamp [43] and Judge [38].

According to tough's research [26, 44], subjective burden refers to the emotional or psychological impact on caregiving tasks on caregivers, and objective burden refers to the amounts of activities the caregiver provides, as well as the time burden of providing support for these tasks. In this study, we defined the subjective burden as caregiver personal perceived burden and the objective burden as daily care time.
We employed the Chinese version of Zarit Burden Interview (ZBI), a widely used scale with proven statistical power [45-47], to measure the subjective burden of caregivers. The scale includes 22 questions rated on a 5-point scale [42, 48]. Caregivers assigned a numerical value between 0 to 4 for each aspect of their burdens, with higher numbers corresponding to higher perceived burdens. The ZBI summary score combines the responses to generate a numerical overall subjective burden ranging from 0 to 88 . According to Lu et. al (2009) [48], the Chinese version of ZBI had high internal consistency (Cronbach's $\alpha=0.875, \mathrm{KMO}=0.867$ ), and goodness of fit in confirmatory factor analysis (RMSEA $=0.077$; $\mathrm{CFI}=0.841$; NFI $=0.802$; GFI $=0.886$, which proved the good reliability and validity of the Scale [44]. In this study, Cronbach's alpha of the scale was 0.943 $(\mathrm{p}<0.000)$ and KMO of the scale was $0.935(\mathrm{p}<0.000)$.

\section{Sample size calculation}

The sample size calculation was performed by the following formula: $N=\frac{u_{\alpha / 2}^{2} \pi(1-\pi)}{\delta^{2}} \quad(\pi:$ overall rate $)$ [49]. Because the rate of patients with critical illness and their caregivers is unknown in the full population. We assume that the $\pi=0.5[49,50]$. In this study, $\pi=0.5, u_{\alpha / 2}=1.96, \delta=0.1 \pi=0.05$. The calculated sample size was 385 . Considering $20 \%$ non-responders [51], we found a minimum sample size of 462. A stratified cluster sampling method was used. Samples with missing exclusion information as well as those that did not meet the inclusion criteria were excluded. We finally obtain 554 valid questionnaire responses from 77 villages.

\section{Ethical considerations}

Before the investigation, signed informed consent was obtained from each prospective participant. The Academic Research Ethics Committee of Shandong

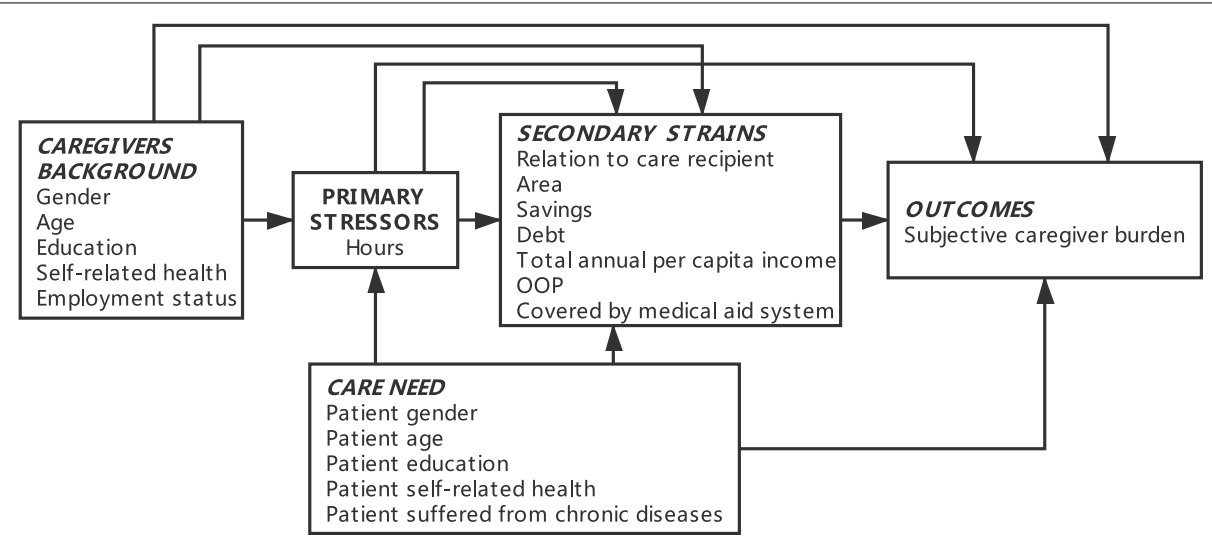

Fig. 2 Stress process model for overview of the study aims 
University validated this form of consent and approved the research proposal.

\section{Statistical analysis}

Data was analyzed using Stata 14.0. Normality of the variables was verified using the Shapiro-Francia W' test prior to analysis. Categorical variables were presented with absolute and relative frequencies, and continuous variables were presented with median and IQRs. Wilcoxon rank sum test for binary variables, Kruskal Wallis rank sum test for polytomous variables, and Spearman rank correlation test for continuous variables were used to identify factors that were significantly associated with caregiver burden. OLS regression was employed to explore these associations after controlling the confounding factors. Multicollinearity was tested using the variance inflation factor (VIF). The VIF of each variable was less than 10 , which proved no multicollinearity existed.

\section{Results}

\section{Descriptive results}

The average ZBI scores in this study was $30.37 \pm 19.04$ $(\mathrm{n}=554)$. Sightly more than half of informal caregivers were female $(50.90 \%)$ and unemployed $(53.61 \%)$, as shown in Table $1.53 .79 \%$ of family caregivers were 65 years old or younger, $59.21 \%$ had at least a junior high school education, and $79.24 \%$ had good self-rated health. A supermajority of informal caregivers were spouses $(79.78 \%)$ whose caregiving time generally averaged under12 h/d (63.36\%). Most surveyed families had no savings (63.18\%) and no debt (58.3\%). Even though the sampled patients were all critically ill, $93.68 \%$ were not covered by any medical aid system.

\section{Univariate analysis}

Summary statistics illustrated that caregiver age, patient relationship, hours spent caregiving, family debt, total annual per capita income, OOP costs, and their patient's self-rated health were all significantly associated with the ZBI score of family caregivers (Table1).

\section{Multivariate regression analyses}

OLS regression analysis model results are illustrated in Table 2. Younger caregivers (aged 65 and below) and more educated caregivers (with at least secondary schooling) faced greater subjective burdens than their counterparts, with significance of $-6.05 ; 95 \% \mathrm{CI}, 10.68$ to -1.42; $\mathrm{P}=0.011$ and $3.61 ; 95 \% \mathrm{CI}, 0.49$ to $6.73 ; \mathrm{p}=0.023$, respectively. ZBI scores of spouse caregivers were significantly lower than those of other family caregivers (4.12; 95\%CI, 0.42 to $7.81 ; \mathrm{P}=0.029$ ).

In addition, subjective burdens were proportional to objective burdens. For example, the ZBI of caregivers who spent more than 13 hours per day caring for patients was significantly higher than that of other caregivers (5.03; 95\%CI, 1.44 to $8.61 ; \mathrm{P}=0.006$ ). Higher OOP costs of critical diseases, the heavier subjective burden of the caregivers $(1.28 ; 95 \% \mathrm{CI},-0.06$ to $2.63 ; \mathrm{p}=0.062)$. Meanwhile, as family per capita income improved, the subjective burden of informal caregivers decreased. Formal medical aid systems also played a positive role in reducing subjective caregiving burdens $(-7.31 ; 95 \% \mathrm{CI},-13.23$ to $-1.40 ; \mathrm{p}=0.016$ ). Finally, the subjective caregiving burdens increased when care recipients were older (aged 66 years and above $(\mathrm{P}=0.884)$, had poorer self-reported health $(\mathrm{P}=0.000)$, or had other chronic diseases in addition to their critical illnesses $(\mathrm{P}=0.138)$.

\section{Discussion}

Critical illnesses have influence both patients and their families. Our study focused on the informal caregivers of patients with critical illnesses and found that more than a quarter of family caregivers faced a moderate to severe burden with a ZBI greater than 40 . The average ZBI score in this study was $30.37 \pm 19.04$. Subjective caregiver burden in our study were heavier than those reported other Chinese studies on oncology, rheumatoid arthritis, and schizophrenia, in which caregivers generally had a mild or moderate burden [52-54]. One possible explanation is that the population involved in this study was caregivers of critically ill patients in rural areas, who have relatively lower incomes and fewer assets and therefore shoulder heavier financial burdens. Additionally, the health status of cancer patients may change suddenly and unpredictably, and this uncertainty increases subjective care burden for family caregivers [55]. Other studies of informal caregivers for advanced cancer patients similarly found that a substantial proportion of informal caregivers face substantial subjective burden and are simultaneously faced with decreased quality of life, increased risk of depression, and a decreased ability to work or engage in normal activity [56-58].

Our results showed that younger informal caregivers (65 and below years) had significantly higher ZBI scores than their older counterparts, which is in line with Cain and Wicks's study [59,60]. Younger informal caregivers must fulfill varied and at times conflicting responsibilities in caregiving, work, and social life. We also found that spouse caregivers experience a significantly higher subjective burden than other relatives who provide care, which is consistent with studies of India and rural China though contrary to a Dutch study $[34,43,46]$. This finding was not surprising in a Chinese context, since spouses who live with their patients would face fewer role conflicts. However, other family members who care for patients with critical illnesses may experience subjective 
Table 1 Informal caregivers, Patients and Secondary role strains Characteristics ( $N=554)$

\begin{tabular}{|c|c|c|c|}
\hline \multirow[t]{2}{*}{ Variable } & \multicolumn{3}{|c|}{ Burden interview } \\
\hline & $\mathrm{N}(\%)$ & Test Statistic & $\mathbf{P}$ \\
\hline \multicolumn{4}{|l|}{ Caregivers } \\
\hline \multicolumn{4}{|l|}{ Gender } \\
\hline Male & $272(49.10)$ & -0.11 & 0.916 \\
\hline Female & $282(50.90)$ & & \\
\hline \multicolumn{4}{|l|}{ Age } \\
\hline 65 and below & 298(53.79) & 2.41 & 0.016 \\
\hline 66 and above & $256(46.21)$ & & \\
\hline \multicolumn{4}{|l|}{ Education } \\
\hline Primary schools and below & $226(40.79)$ & -0.82 & 0.415 \\
\hline Secondary and above & $328(59.21)$ & & \\
\hline \multicolumn{4}{|l|}{ Self-rated health } \\
\hline Good & 439(79.24) & 1.98 & 0.048 \\
\hline Poor & 115(20.76) & & \\
\hline \multicolumn{4}{|l|}{ Employment status } \\
\hline Employment & 257(46.39) & 0.68 & 0.499 \\
\hline Unemployment & $291(53.61)$ & & \\
\hline \multicolumn{4}{|l|}{ Caregiver } \\
\hline Spouse & $442(79.78)$ & -2.40 & 0.016 \\
\hline Other relatives & $112(20.22)$ & & \\
\hline \multicolumn{4}{|l|}{ Objective burden } \\
\hline \multicolumn{4}{|l|}{ Caregiving hours per day } \\
\hline$\leq 4$ & $170(30.69)$ & 19.58 & 0.000 \\
\hline $5-8$ & $81(14.62)$ & & \\
\hline $9-12$ & $100(18.05)$ & & \\
\hline$>13$ & 203(36.64) & & \\
\hline \multicolumn{4}{|l|}{ Patients with critical illness } \\
\hline \multicolumn{4}{|l|}{ Gender } \\
\hline Male & 275(49.64) & 0.53 & 0.605 \\
\hline Female & $279(50.36)$ & & \\
\hline \multicolumn{4}{|l|}{ Age } \\
\hline 65 and below & $280(50.54)$ & 0.125 & 0.900 \\
\hline 66 and above & $274(49.46)$ & & \\
\hline \multicolumn{4}{|l|}{ Education } \\
\hline Illiterate & 113(20.40) & -1.82 & 0.069 \\
\hline Educated & $441(79.60)$ & & \\
\hline \multicolumn{4}{|l|}{ Self-rated health } \\
\hline Good & $251(45.31)$ & 7.72 & 0.000 \\
\hline Poor & 303(54.69) & & \\
\hline \multicolumn{4}{|c|}{ Whether suffered from chronic diseases } \\
\hline Yes & 194(35.02) & 1.92 & 0.138 \\
\hline No & $360(64.98)$ & & \\
\hline \multicolumn{4}{|l|}{ Secondary stressor } \\
\hline \multicolumn{4}{|l|}{ Savings } \\
\hline Yes & $204(36.82)$ & 1.53 & 0.055 \\
\hline No & $350(63.18)$ & & \\
\hline \multicolumn{4}{|l|}{ Debt } \\
\hline Yes & $231(41.70)$ & 5.884 & 0.000 \\
\hline No & $323(58.30)$ & & \\
\hline
\end{tabular}


Table 1 (continued)

\begin{tabular}{|c|c|c|c|}
\hline \multirow[t]{2}{*}{ Variable } & \multicolumn{3}{|l|}{ Burden interview } \\
\hline & N (\%) & Test Statistic & $\mathbf{P}$ \\
\hline \multicolumn{4}{|l|}{ Total annual per capita income $e^{\mathrm{a}}$} \\
\hline Q1 & 139(25.09) & 36.14 & 0.000 \\
\hline Q2 & 137(24.73) & & \\
\hline Q3 & 139(25.09) & & \\
\hline Q4 & 139(25.09) & & \\
\hline \multicolumn{4}{|l|}{ Whether covered by medical aid system } \\
\hline No & 519(93.68) & 0.72 & 0.473 \\
\hline Yes & $35(6.32)$ & & \\
\hline Log OOP of critical illness (Median, IQR) & 10.30(9.66,10.82) & Spearman's rho $=0.1183$ & 0.005 \\
\hline \multicolumn{4}{|l|}{ Area } \\
\hline Yantai & 187(33.75) & 11.69 & 0.003 \\
\hline Weifang & 225(40.61) & & \\
\hline Heze & $142(25.63)$ & & \\
\hline
\end{tabular}

Note: ${ }^{\text {a }}$ Quartile $1(\mathrm{Q} 1)$ is the poorest and Quartile $4(\mathrm{Q} 4)$ is the richest

Table 2 OLS regression analysis of informal caregivers' burden related factors

\begin{tabular}{|c|c|c|c|c|c|}
\hline Factors & $\beta$ & SE & $\mathrm{t}$ & P-Values & $95 \% \mathrm{Cl}$ for $\beta$ \\
\hline Gender of caregivers: Female (ref: Male) & -0.54 & 2.07 & -0.26 & 0.795 & $(-4.60,3.52)$ \\
\hline Age of caregivers: 66 and above (ref: 65 and below) & -6.05 & 2.36 & -2.57 & 0.011 & $(-10.68,-1.42)$ \\
\hline $\begin{array}{l}\text { Education of caregivers: Secondary and above (ref: Primary } \\
\text { schools and below) }\end{array}$ & 3.61 & 1.59 & 2.27 & 0.023 & $(0.49,6.73)$ \\
\hline Self-rated health of caregivers: Poor (ref: Good) & -1.33 & 1.87 & -0.71 & 0.477 & $(-5.01,2.34)$ \\
\hline Employment status: Unemployment (ref: Employment) & -0.66 & 1.55 & -0.42 & 0.672 & $(-3.71,2.39)$ \\
\hline Caregiver: other relatives (ref: Spouse) & 4.12 & 1.88 & 2.19 & 0.029 & $(0.42,7.81)$ \\
\hline \multicolumn{6}{|l|}{ Caregiving Time (ref: $\leq 4$ ) } \\
\hline $5-8$ & -0.22 & 2.30 & -0.10 & 0.923 & $(-4.75,4.30)$ \\
\hline $9-12$ & 4.41 & 2.15 & 2.05 & 0.041 & $(0.18,8.63)$ \\
\hline$>13$ & 5.02 & 1.83 & 2.75 & 0.006 & $(1.44,8.61)$ \\
\hline Gender of patients: Female (ref: Male) & -2.56 & 2.03 & -1.26 & 0.207 & $(-6.55,1.42)$ \\
\hline Age of patients: 66 and above (ref: 65 and below) & 5.52 & 2.34 & 2.36 & 0.018 & $(0.93,10.11)$ \\
\hline Education of patients: Educated (ref: Illiterate) & 2.99 & 1.98 & 1.51 & 0.131 & $(-0.90,6.88)$ \\
\hline Self-rated health of patient: Poor (ref: Good) & 10.61 & 1.58 & 6.72 & 0.000 & $(7.51,13.71)$ \\
\hline Patients suffered from chronic diseases: No (ref: Yes) & -5.31 & 2.49 & -2.13 & 0.033 & $(-10.19,-0.42)$ \\
\hline Savings: No (ref: Yes) & -1.52 & 1.58 & -0.96 & 0.336 & $(-4.61,1.58)$ \\
\hline Debt: No (ref: Yes) & -6.88 & 1.63 & -4.22 & 0.000 & $(-10.08,-3.68)$ \\
\hline \multicolumn{6}{|l|}{ Total annual per capita income (ref: Q1) ${ }^{\mathrm{a}}$} \\
\hline Q2 & -5.10 & 2.08 & -2.45 & 0.015 & $(-9.20,-1.01)$ \\
\hline Q3 & -7.20 & 2.07 & -3.47 & 0.001 & $(-11.26,-3.13)$ \\
\hline Q4 & -11.13 & 2.16 & -5.16 & 0.000 & $(-15.37,-6.90)$ \\
\hline Log OOP & 1.28 & 0.69 & 1.87 & 0.062 & $(-0.06,2.63)$ \\
\hline Covered by medical aid system: Yes (ref: No) & -7.31 & 3.01 & -2.43 & 0.016 & $(-13.23,-1.40)$ \\
\hline \multicolumn{6}{|l|}{ Area (ref: Yantai) } \\
\hline Weifang & -3.70 & 1.76 & -2.10 & 0.036 & $(-7.15,-0.24)$ \\
\hline Heze & -0.22 & 2.09 & -0.10 & 0.918 & $(-4.31,3.88)$ \\
\hline
\end{tabular}

Note: ${ }^{\text {a }}$ Quartile $1(\mathrm{Q} 1)$ is the poorest and Quartile $4(\mathrm{Q} 4)$ is the richest 
burdens due to their variable family roles $[46,61]$. Parental caregivers experience more anxiety, and child caregivers face varied pressures such as weakened social support, lower income, and conflicting demands on time from work and childcare.

Our results displayed the same codirectional relationships between objective and subjective burdens associated with background factors found in previous studies $[33,62,63]$. We found that $54.69 \%$ of caregivers cared for patients for more than 8 hours per day, and $36.64 \%$ cared for patients for more than 12 hours per day. This substantial time investment limits self-directed activities such as socialization, entertainment, and other activities, let alone normal work [20,64]. Prolonged periods of mental stress, physical exhaustion, and lack of social support can impose a financial and psychological burden on caregivers, often lasting months or years [65]. Though longterm care insurance is increasingly available for urban employees, most rural patients in China often lack coverage for their post-discharge care and minimal support for family caregivers. Caregivers receive minimal support of any kind, either in their capacity as caregiver or as an individual [66].The situation is even worse for caregivers who are themselves sick [67]. That said, providing home inpatient support for family caregivers has been shown to substantially relieve psychological stress and to improve caregivers' health and quality of life [11]. Additionally, a study of 18 European countries found that availability of formal long-term care resources mitigated the negative externalities of informal care [68]. In light of these findings, we recommend exploring more caregiving channels, expanding the types of services and the duration of care provided by health care systems, and increasing the psychological care and skill training available to caregivers $[11,69,70]$. Such an approach could mitigate stress and perceived burdens for caregivers and improve patient and family outcomes $[43,71]$.

Our study found that financial burdens worsen subjective burdens. Higher OOP costs and lower income levels generate higher burdens, as noted in previous studies [72]. Unexpectedly, however, caregivers for families with debt had lower subjective burdens. This may be explained by the fact that families with debt have better social relationships relative to other families, possibly enjoying financial support from relatives and friends [73]. Moreover, low incomes and poverty may generate pessimism, frustration, and interpersonal anxiety and rejection, attitudes which may prevent effective engagement with potential social support mechanisms $[26,74]$. Support from relatives, friends, communities, and village doctors may mitigate these negative attitudes [75]. Furthermore, increased socioeconomic support or insurance for informal family caregivers could improve patient and family outcomes [76].

Medical aid systems can also reduce caregiving burdens $[77,78]$. A Nepalese study found that communitybased health insurance and accessible medicine reduce the economic burden associated with disease [79]. Unfortunately, healthcare coverage in rural Shandong is limited, and only $6.32 \%$ of our sample patient population had access to such coverage. In China, critical illness insurance for diseases with high OOP costs began in 2012 for rural residents, and was expanded to cover all urban and rural residents in 2015 [80, 81]. However, our study found no correlation between critical illness insurance policies and subjective caregiver burdens, possibly because critical illness insurance does not cover post-discharge medical care and associated costs. Our study suggests that insurance should cover both direct medical burdens and attempt to mitigate the indirect economic burdens and intangible psychological burden of major diseases. Thirdparty liability insurance may reduce the economic burden of critical illnesses [79].

\section{Limitations}

Because of the cross-sectional design, causality cannot be inferred in this study's results, since only correlates can be examined. In addition, because the study encompassed a larger number of diseases and had limited samples in each category, there is no classification analysis to analyze the caregiver burden in different situations. Because the subjects of our study were rural residents, the results may be affected by self-reported measurement bias and may not be easily generalized. Despite these limitations, our study clearly illustrates the subjective burdens of caregivers of critically ill patients in rural areas. Future research may further explore the role of each factor.

\section{Conclusions}

Informal caregivers of patients with critical illnesses are confronted with heavier subjective burdens than other caregivers, due to stress produced by lengthy care, emotional exhaustion, and financial burdens shared with the patients. Optimal insurance and social policies should address both direct medical burdens as well as the intangible psychological burden of critical diseases. We therefore recommend (1) building a social support system for patients with critical illness beyond simple financial support, (2) focusing on caregivers' mental health and conducting early interventions on their behalf, and (3) expanding long-term care insurance to facilitate formal care. 


\section{Abbreviations}

ZBI: Zarit Burden Interview; OOP: Out-of-Pocket.

\section{Acknowledgements}

We thank the officials of health agencies, all participants and staffs at the study sites for making this study possible.

\section{Authors' contributions}

Study design: Jiajia Li, Shixue Li. Collection and assembly of data: Jiajia Li, Wenhao Fu, Feng Fang. Data analysis and interpretation: Wenhao Fu. Manuscript writing: Wenhao Fu, Jiajia Li. Formal analysis: Dan Zhao, Wenting Hao. Final approval of manuscript: All authors. Accountable for all aspects of the work: All authors.

\section{Funding}

This work was supported by the Natural Science Foundation of China (NSFC), No.71673170, Humanities and Social Science Foundation of Ministry of Education, China, No. 21YJC630060, Natural Science Foundation of China (NSFC), No.71303137, and Innovation Foundation of Youth Team of Shandong University, No. IFYT1810.

\section{Availability of data and materials}

The data used during this study are available from the corresponding authors on reasonable request.

\section{Declarations}

\section{Ethics approval and consent to participate}

Before the investigation, signed informed consent was obtained from each prospective participant, and the Academic Research Ethics Committee of Shandong University validated this form of consent and approved the research proposal (access number: 20190101). All methods were carried out in accordance with relevant guidelines and regulations.

\section{Consent for publication}

Not applicable.

\section{Competing interests}

The authors declare that they have no conflicts of interest.

\section{Author details}

${ }^{1}$ Centre for Health Management and Policy Research, School of Public Health, Cheeloo College of Medicine, Shandong University, Jinan 250012, China. ${ }^{2} \mathrm{NHC}$ Key Lab of Health Economics and Policy Research (Shandong University), Jinan 250012, China.

Received: 21 March 2021 Accepted: 27 September 2021

Published online: 22 October 2021

\section{References}

1. Hammond T, Weinberg MK, Cummins RA. The dyadic interaction of relationships and disability type on informal carer subjective well-being. Qual Life Res. 2014;23(5):1535-42.

2. Dunbar SB, Khavjou OA, Bakas T, Hunt G, Kirch RA, Leib AR, et al. Projected Costs of Informal Caregiving for Cardiovascular Disease: 2015 to 2035 A Policy Statement From the American Heart Association. Circulation. 2018;137(19):E558-77.

3. Swartz K, Collins LG. Caregiver Care. Am Fam Physician. 2019;99(11):699-706

4. Antonella S, Flavia V, Daniela T, Giuseppe T, Daniele S. The 'Charter of Rights for Family Caregivers.' The role and importance of the caregiver: an Italian proposal. Esmo Open. 2017;2(5).

5. Seidel D, Thyrian JR. Burden of caring for people with dementia - comparing family caregivers and professional caregivers. A descriptive study. J Multidiscip Healthc. 2019:12:655-63.
6. Takahashi M, Tanaka K, Miyaoka H. Depression and associated factors of informal caregivers versus professional caregivers of demented patients. Psychiatry Clin Neurosci. 2005;59(4):473-80.

7. Miyamoto Y, Tachimori H, Ito H. Formal Caregiver Burden in Dementia: Impact of Behavioral and Psychological Symptoms of Dementia and Activities of Daily Living. Geriatr Nurs. 2010;31(4):246-53.

8. Kunkle R, Chaperon C, Berger AM. Formal Caregiver Burden in Nursing Homes: An Integrative Review. West J Nurs Res. 2020.

9. Pearlin LI, Mullan JT, Semple SJ, Skaff MM. CAREGIVING AND THE STRESS PROCESS - AN OVERVIEW OF CONCEPTS AND THEIR MEASURES. Gerontologist. 1990;30(5):583-94.

10. Schmidt AE, llinca S, Schulmann K, Rodrigues R, Principi A, Barbabella $F$, et al. Fit for caring: factors associated with informal care provision by older caregivers with and without multimorbidity. Eur J Ageing. 2016;13(2):103-13.

11. Logsdon RG. Dementia: psychosocial interventions for family caregivers. Lancet. 2008;372(9634):182-3.

12. Bekdemir A, Ilhan N. Predictors of Caregiver Burden in Caregivers of Bedridden Patients. J Nurs Res. 2019;27(3).

13. Kayser K, Watson LE, Andrade JT. Cancer as a "we-disease": Examining the process of coping from a relational perspective. Fam Syst Health. 2007;25(4):404-18.

14. Celis JE, Heitor M. Towards a mission-oriented approach to cancer in Europe: an unmet need in cancer research policy. Mol Oncol. 2019;13(3):502-10.

15. Critical illness insurance knowledge Q \& A [http://www.cmda.net/ tzgg11/10010.jhtml]

16. Specification for the use of the definition of disease in critical illness insurance (Rev. 2020) [http://www.iachina.cn/art/2020/11/5/art_8616_ 104704.html]

17. Fang $P$, Pan Z, Zhang $X$, Bai $X$, Gong $Y$, Yin X. The effect of critical illness insurance in China. Medicine. 2018;97(27).

18. Hu S, Tang S, Liu Y, Zhao Y, Escobar ML, de Ferranti D, et al. Reform of how health care is paid for in China: challenges and opportunities (vol 372, pg 1846, 2008). Lancet. 2009:374(9686):292.

19. Lee K-C, Yiin J-J, Chao Y-F. Effect of integrated caregiver support on caregiver burden for people taking care of people with cancer at the end of life: A cohort and quasi-experimental clinical trial. Int J Nurs Stud. 2016;56:17-26.

20. Souza ALR, Guimaraes RA, de Araujo VD, de Assis RM. de Almeida Cavalcante Oliveira LM, Souza MR, Nogueira DJ, Barbosa MA: Factors associated with the burden of family caregivers of patients with mental disorders: a cross-sectional study. BMC Psychiatry. 2017;17(1):353.

21. Holtslander L, Baxter S, Mills K, Bocking S, Dadgostari T, Duggleby W, et al. Honoring the voices of bereaved caregivers: a Metasummary of qualitative research. BMC Palliat Care. 2017;16.

22. Caregiver Health [http://www.caregiveroc.org/documents/Fact-Sheets/ Caregiver-Health-Rev-12-12.pdf.pdf]

23. Sherwood PR, Given CW, Given BA, Von Eye A. Caregiver burden and depressive symptoms: Analysis of common outcomes in caregivers of elderly patients. J Aging Health. 2005;17(2):125-47.

24. Hoenig J, Hamilton MW. SCHIZOPHRENIC PATIENT IN COMMUNITY AND HIS EFFECT ON HOUSEHOLD. Int J Soc Psychiatry. 1966;12(3):165-76.

25. Jones SL. The association between objective and subjective caregiver burden. Arch Psychiatr Nurs. 1996;10(2):77-84.

26. Tough H, Brinkhof MWG, Siegrist J, Fekete C, Swi SCISG. Social inequalities in the burden of care: a dyadic analysis in the caregiving partners of persons with a physical disability. Int J Equity Health. 2020;19(1).

27. Zarit SH, Todd PA, Zarit JM. SUBJECTIVE BURDEN OF HUSBANDS AND WIVES AS CAREGIVERS - A LONGITUDINAL-STUDY. Gerontologist. $1986 ; 26(3): 260-6$

28. Support for caregivers in the USA. Lancet. 2020;395(10225):660.

29. Anderson EW, White KM. "It Has Changed My Life": An Exploration of Caregiver Experiences in Serious IIIness. Am J Hosp Palliat Med. 2018;35(2):266-74.

30. Adelman RD, Tmanova LL, Delgado D, Dion S, Lachs MS. Caregiver Burden A Clinical Review. Jama-J Am Med Assoc. 2014;311(10):1052-9.

31. Pinquart $M$, Sorensen $S$. Associations of stressors and uplifts of caregiving with caregiver burden and depressive mood: A meta-analysis. J Gerontol Series B-Psychol Sci Soc Sci. 2003;58(2):P112-28. 
32. Ge L, Mordiffi SZ. Factors Associated With Higher Caregiver Burden Among Family Caregivers of Elderly Cancer Patients A Systematic Review. Cancer Nurs. 2017;40(6):471-8.

33. Han Y, Liu Y, Zhang X, Tam W, Mao J, Lopez V. Chinese family caregivers of stroke survivors: Determinants of caregiving burden within the first six months. J Clin Nurs. 2017;26(23-24):4558-66.

34. Roopchand-Martin S, Creary-Yan S. Level of Caregiver Burden in Jamaican Stroke Caregivers and Relationship between Selected Sociodemographic Variables. West Indian Med J. 2014:63(6):605-9.

35. Durante A, Greco A, Annoni AM, Steca P, Alvaro R, Vellone E. Determinants of caregiver burden in heart failure: does caregiver contribution to heart failure patient self-care increase caregiver burden? Eur J Cardiovasc Nurs. 2019;18(8):691-9.

36. China Health Statistics Yearbook. China: National Health Commission of the People's Republic of. China; 2020.

37. Ice GH, Sadruddin AFA, Vagedes A, Yogo J, Juma E. Stress associated with caregiving: An examination of the stress process model among Kenyan Luo elders. Soc Sci Med. 2012;74(12):2020-7.

38. Judge KS, Menne HL, Whitlatch CJ. Stress process model for individuals with dementia. Gerontologist. 2010;50(3):294-302.

39. van Groenou MB, Jacobs M, Zwart-Olde I, Deeg DJH. Mixed care networks of community-dwelling older adults with physical health impairments in the Netherlands. Health Soc Care Community. 2016;24(1):95-104.

40. Chou Y-C, Fu L-Y, Lin L-C, Lee Y-C. Predictors of subjective and objective caregiving burden in older female caregivers of adults with intellectual disabilities. Int Psychogeriatr. 2011;23(4):562-72.

41. Swinkels J, van Tilburg T, Verbakel E, van Groenou MB. Explaining the Gender Gap in the Caregiving Burden of Partner Caregivers. J Gerontol Series B-Psychol Sci Soc Sci. 2019;74(2):309-17.

42. Zarit SH, Reever KE, Bachpeterson J. RELATIVES OF THE IMPAIRED ELDERLY - CORRELATES OF FEELINGS OF BURDEN. Gerontologist. 1980;20(6):649-55.

43. Oldenkamp M, Hagedoorn M, Slaets J, Stolk R, Wittek R, Smidt N. Subjective burden among spousal and adult-child informal caregivers of older adults: results from a longitudinal cohort study. BMC Geriatr. 2016;16(1).

44. Tough H, Brinkhof MW, Siegrist J, Fekete C. Subjective Caregiver Burden and Caregiver Satisfaction: The Role of Partner Relationship Quality and Reciprocity. Arch Phys Med Rehabil. 2017;98(10):2042-51.

45. Li C, Miao L, Gao X, Zheng L, Su X, Hui H, et al. Factors Associated with Caregiver Burden in Primary Caregivers of Patients with Adolescent Scoliosis: A Descriptive Cross-Sectional Study. Med Sci Monit. 2018;24:6472-9.

46. Yu Y, Li T-x, Li Y-I, Qiu D, Xi S-j. Xiao S-y, Tebes JK: A cross-sectional study on spouse and parent differences in caregiving experiences of people living with schizophrenia in rural China. BMC Psychiatry. 2020;20(1).

47. Sun X, Ge J, Meng H, Chen Z, Liu D. The Influence of Social Support and Care Burden on Depression among Caregivers of Patients with Severe Mental Illness in Rural Areas of Sichuan, China. Int J Environ Res Public Health. 2019;16(11).

48. Lu L, Wang L, Yang X, Feng Q. Zarit Caregiver Burden Interview: Development, reliability and validity of the Chinese version. Psychiatry Clin Neurosci. 2009;63(6):730-4.

49. Sun ZQ XY, editors. : Medical Statistics (Four Edition). China: Beijing: People'sMedical Publishing House(PMPH); 2002.

50. Zhenqiu Sun YX: Medical statistics. Beijing: People's Medical Publishing House

51. Ahmad Zubaidi ZS, Ariffin F, Oun CTC, Katiman D. Caregiver burden among informal caregivers in the largest specialized palliative care unit in Malaysia: a cross sectional study. BMC Palliat Care. 2020;19(1).

52. Luo J, Zhou Y, Liu H, Hu J. Factors related to the burden of family caregivers of elderly patients with spinal Tumours in Northwest China. BMC Neurol. 2020;20(1).

53. Ru J, Ma J, Niu H, Chen Y, Li L, Liu Y, et al. Burden and depression in caregivers of patients with rheumatoid arthritis in China. Int J Rheum Dis. 2019;22(4):608-13.

54. Yu Y, Liu Z-W, Zhou W, Chen X-C, Zhang X-Y, Hu M, et al. Assessment of Burden Among Family Caregivers of Schizophrenia: Psychometric Testing for Short-Form Zarit Burden Interviews. Front Psychol. 2018;9.

55. Saria MG, Nyamathi A, Phillips LR, Stanton AL, Evangelista L, Kesari S, et al. The Hidden Morbidity of Cancer Burden in Caregivers of Patients with Brain Metastases. Nurs Clin North Am. 2017;52(1):159-+.
56. Borges EL, Franceschini J, Degani Costa LH, Godoy Fernandes AL, Jamnik S, Santoro IL. Family caregiver burden: the burden of caring for lung cancer patients according to the cancer stage and patient quality of life. J Bras Pneumol. 2017;43(1):18-23.

57. Jadalla A, Page M, Ginex P, Coleman M, Vrabel M, Bevans M. Family Caregiver Strain and Burden A systematic review of evidence-based interventions when caring for patients with cancer. Clin J Oncol Nurs. 2020;24(1):31-50.

58. Chua CKT, Wu JT, Wong YY, Qu L, Tan YY, Neo PSH, et al. Caregiving and Its Resulting Effects-The Care Study to Evaluate the Effects of Caregiving on Caregivers of Patients with Advanced Cancer in Singapore. Cancers. 2016;8(11)

59. Cynthia J. Cain MNW: Caregiver Attributes as Correlates of Burden in Family Caregivers Coping With Chronic Obstructive Pulmonary Disease. J Fam Nurs. 2000;6(1):46-68.

60. Grant M, Cavanagh A, Yorke J. The impact of caring for those with chronic obstructive pulmonary disease (COPD) on carers' psychological wellbeing: A narrative review. Int J Nurs Stud. 2012;49(11):1459-71.

61. Haines KJ, Denehy L, Skinner EH, Warrillow S, Berney S. Psychosocial Outcomes in Informal Caregivers of the Critically III: A Systematic Review. Crit Care Med. 2015;43(5):1112-20.

62. Martins Gratao AC, da Silva Talmelli LF, Figueiredo LC, Rosset I, Freitas CP, Partezani Rodrigues RA. Functional dependency of older individuals and caregiver burden. Rev Esc Enferm USP. 2013;47(1):134-41.

63. Doser K, Norup A. Caregiver burden in Danish family members of patients with severe brain injury: The chronic phase. Brain Inj. 2016;30(3):334-42.

64. Suri RS, Larive B, Garg AX, Hall YN, Pierratos A, Chertow GM, et al. Burden on caregivers as perceived by hemodialysis patients in the Frequent Hemodialysis Network (FHN) trials. Nephrol Dial Transplant. 2011;26(7):2316-22.

65. Chang S, Zhang Y, Jeyagurunathan A, Lau YW, Sagayadevan V, Chong SA, et al. Providing care to relatives with mental illness: reactions and distress among primary informal caregivers. BMC Psychiatry. 2016;16.

66. S-kA H. Elliott TR, Martin R, Uswatte G: Family caregivers'attributions about care-recipient behaviour: Does caregiver relationship satisfaction mediate the attribution-distress relationship? Br J Health Psychol. 2011;16:642-59.

67. Rha SY, Park Y, Song SK, Lee CE, Lee J. Caregiving burden and the quality of life of family caregivers of cancer patients: the relationship and correlates. Eur J Oncol Nurs. 2015;19(4):376-82.

68. Verbakel E. Informal caregiving and well-being in Europe: What can ease the negative consequences for caregivers? J Eur Soc Policy. 2014;24(5):424-41.

69. Carretero S, Garces J, Rodenas F, Sanjose V. The informal caregiver's burden of dependent people: Theory and empirical review. Arch Gerontol Geriatr. 2009;49(1):74-9.

70. Unver V, Basak T, Tosun N, Aslan O, Akbayrak N. Care Burden and SelfEfficacy Levels of Family Caregivers of Elderly People in Turkey. Holist Nurs Pract. 2016;30(3):166-73.

71. Mirsoleymani SR, Rohani C, Matbouei M, Nasiri M, Vasli P. Predictors of caregiver burden in Iranian family caregivers of cancer patients. J Educ Health Promot. 2017;6:91.

72. Loughnan ME, Nicholls N, Tapper NJ. Demographic, seasonal, and spatial differences in acute myocardial infarction admissions to hospital in Melbourne Australia. Int J Health Geogr. 2008;7.

73. Hu K. De Rosa E. Anderson AK: Differential temporal salience of earning and saving. Nature Communications; 2018. p. 9.

74. Braun M, Mikulincer M, Rydall A, Walsh A, Rodin G. Hidden Morbidity in Cancer: Spouse Caregivers. J Clin Oncol. 2007;25(30):4829-34.

75. Zhong Y, Wang J, Nicholas S. Social support and depressive symptoms among family caregivers of older people with disabilities in four provinces of urban China: the mediating role of caregiver burden. BMC Geriatr. 2020;20(1):3.

76. Hashimoto K, Wang M, He B, Wang Y, Wu F, Chen $X$, et al. Depression among Low-Income Female Muslim Uyghur and Kazakh Informal Caregivers of Disabled Elders in Far Western China: Influence on the Caregivers' Burden and the Disabled Elders' Quality of Life. Plos One. 2016;11(5):e0156382.

77. Gotsadze G, Murphy A, Shengelia N, Zoidze A. Healthcare utilization and expenditures for chronic and acute conditions in Georgia: Does benefit package design matter? BMC Health Serv Res. 2015;15. 
78. Su D, Chen Y, Gao H, Li H, Chang J, Lei S, et al. Is There a Difference in the Utilisation of Inpatient Services Between Two Typical Payment Methods of Health Insurance? Evidence from the New Rural Cooperative Medical Scheme in China. Int J Environ Res Public Health. 2019;16(8).

79. Swe KT, Rahman MM, Rahman MS, Saito E, Abe SK, Gilmour S, et al. Cost and economic burden of illness over 15 years in Nepal: A comparative analysis. Plos One. 2018;13(4).

80. Guiding Opinions of the National Development and Reform Commission, the Ministry of Health and other six ministries and commissions on carrying out critically ill insurance for urban and rural residents [http://www. nhc.gov.cn/tigs/s9660/201208/d27ac3e2bdf94780826e80458131a353. shtml]
81. The General Office of the State Council issued the Opinions on Fully Implementing critically ill Insurance for Urban and Rural Residents [http:// www.nhc.gov.cn/tigs/s7847/201508/f7bcca54a01e40af8a7d0771dc0bcc 3d.shtml]

\section{Publisher's Note}

Springer Nature remains neutral with regard to jurisdictional claims in published maps and institutional affiliations.
Ready to submit your research? Choose BMC and benefit from:

- fast, convenient online submission

- thorough peer review by experienced researchers in your field

- rapid publication on acceptance

- support for research data, including large and complex data types

- gold Open Access which fosters wider collaboration and increased citations

- maximum visibility for your research: over $100 \mathrm{M}$ website views per year

At BMC, research is always in progress.

Learn more biomedcentral.com/submissions 